\title{
Reciprocal skeletal phenotypes of PRC2-related overgrowth and Rubinstein-Taybi syndromes: potential role of H3K27 modifications
}

\author{
Daniel Gamu ${ }^{1,2}$ and William T. Gibson ${ }^{1,2}$ \\ ${ }^{1}$ BC Children's Hospital Research Institute, Vancouver, British Columbia V5Z 4H4, Canada; ${ }^{2}$ Department of \\ Medical Genetics, University of British Columbia, Vancouver, British Columbia V6H 3N1, Canada
}

\begin{abstract}
Within histone $\mathrm{H} 3$, lysine 27 (H3K27) is one of the residues that functions as a molecular switch, by virtue of being subject to mutually exclusive post-translational modifications that have reciprocal effects on gene expression. Whereas acetylation of H3K27 is associated with transcriptional activation, methylation at this residue causes transcriptional silencing; these two modifications are mutually exclusive. Establishment of these epigenetic marks is important in defining cellular identity and for maintaining normal cell function, as evidenced by rare genetic disorders of epigenetic writers involved in H3K27 post-translational modification. Polycomb repressive complex (PRC2)-related overgrowth and Rubinstein-Taybi syndrome (RSTS) are respectively associated with impaired H3K27 methylation and acetylation. Whereas these syndromes share commonalities like intellectual disability and susceptibility to cancers, they are generally divergent in their skeletal growth phenotypes, potentially through dysregulation of their opposing H3K27 writer functions. In this review, we discuss the requirement of H3K27 modifications for successful embryogenesis, highlighting data from relevant mouse knockout studies. Although such gene ablation studies are integral for defining fundamental biological roles of methyl- and acetyltransferase function in vivo, studies of partial loss-of-function models are likely to yield more meaningful translational insight into progression of PRC2-related overgrowth or RSTS. Thus, modeling of rare human PRC2-related overgrowth and RSTS variants in mice is needed to fully understand the causative role of aberrant H3K27 modification in the pathophysiology of these syndromes.
\end{abstract}

Corresponding author: wtgibson@bcchr.ca

(c) 2020 Gamu and Gibson This article is distributed under the terms of the Creative Commons Attribution-NonCommercial

License, which permits reuse and redistribution, except for commercial purposes, provided that the original author and source are credited.

Published by Cold Spring Harbor Laboratory Press

doi:10.1101/mcs.a005058

\section{INTRODUCTION}

Although the body's somatic cells typically share the same genome, a plurality of cell types is required to support diverse biological functions. Such diversity demands specialization in the ways the genome is put to use. Successful histogenesis requires the coordinated activation and suppression of lineage-specific genes. To achieve this, cells modify their chromatin structure to allow or restrict these critical loci from transcriptional access. This process involves histones, DNA methylation, and noncoding RNA species (to name a few participants). In particular, core histone proteins undergo post-translational modifications (PTMs) at several key lysine residues; the relative importance of specific PTMs at specific sites is an area of active investigation.

Histone octamers are composed of two copies each of $\mathrm{H} 2 \mathrm{~A}, \mathrm{H} 2 \mathrm{~B}, \mathrm{H} 3$, and $\mathrm{H} 4$. When bound to DNA, they form nucleosomes, the fundamental unit of chromatin. A number 
of histone PTMs alter chromatin state, including phosphorylation, ubiquitination, SUMOylation, ADP ribosylation, deamination, proline isomerization, methylation, and acetylation (Goyal et al. 2019). The combinatorial profile of these histone PTMs is the theoretical basis of the histone code (Strahl and Allis 2000), whereby their presence is linked to distinct biological events (Munshi et al. 2009). Lysine 27 of H3 appears to be a key molecular switch, because either an acetyl group or one or more methyl groups may be attached to it (Bedford et al. 2010; Deevy and Bracken 2019; Sneppen and Ringrose 2019). Acetyl and methyl groups are mutually exclusive at this residue, yet are also associated with opposite transcriptional outcomes. Specifically, addition of an acetyl group to H3K27 (H3K27ac) neutralizes positively charged amino-terminal lysine residues (Kalkhoven 2004), allowing chromatin to relax. Such loosening of DNA-histone and histone-histone contacts results in a more open conformation that permits transcription factor binding and transcriptional activation (Roth et al. 2001). Conversely, H3K27 can be mono-, di-, and trimethylated (H3K27me13 ), which enables tighter chromatin packing and transcriptional silencing (Schuettengruber et al. 2017). Deposition and maintenance of H3K27ac and H3K27me1-3 is controlled by key epigenetic writers and erasers that lay down or remove these moieties in a cell- and context-specific manner. Not surprisingly, functional variants in the enzymes responsible for regulating the H3K27ac mark, or H3K27me1-3 marks, have significant consequences for cells, tissues, and the whole organism, as evidenced by rare diseases associated with mutations of H3K27 writers and erasers. In this review, we focus on the role(s) of the main regulators of H3K27 acetylation and methylation during development, and how mutations that affect these epigenetic writers result in somewhat reciprocal disease phenotypes.

\section{REGULATORS OF THE H3K27 TRANSCRIPTIONAL SWITCH}

The two major groups of proteins that have opposing writer functions at H3K27 are Polycomb group (PcG) and CBP/EP300. Readers are referred to the excellent review by Schuettengruber et al. (2017) for a detailed discussion of all PcG components. Although an appropriate balance of $\mathrm{H} 3 \mathrm{~K} 27$ methylation and acetylation also requires demethylases and deacetylases that erase these histone marks, our focus here is on the writers at H3K27, specifically the Polycomb repressive complex (PRC2) and p300/CBP.

\section{PRC2 Components and General Function}

Multicellular organisms have PRC1 and PRC2, both of which control gene silencing despite having different histone substrates: PRC1 monoubiquitinates H2AK119, whereas PRC2 mono-, di-, and trimethylates H3K27 (Yu et al. 2019). Ultimately, their activity causes chromatin compaction, restricting the physical access of transcriptional machinery to target genes and preventing their expression. PRC2 reader and writer functions enable the inheritance of H3K27me1-3 during cell division; stable transmission of histone marks is required during lineage specification and maintenance, $\mathrm{X}$-chromosome inactivation, genomic imprinting, and segmental patterning during embryogenesis (Wang et al. 2001; Cao et al. 2002; Plath et al. 2003; Silva et al. 2003; Lewis et al. 2004; Ringrose and Paro 2004). The PRC2 core complex is composed of enhancer of zeste (EZH2), embryonic ectoderm development (EED), suppressor of zeste (SUZ12), and retinoblastoma binding protein (RBBP4/7). Furthermore, PRC2 interacts with a combination of accessory proteins, including AE binding protein 2 (AEBP2), jumonji and AT-rich interaction domain containing 2 (JARID2), elongin BC and PRC2-associated protein (EPOP), and Polycomb-like proteins (PCLs) (Schuettengruber et al. 2017; Deevy and Bracken 2019), forming PRC2 subcomplexes (i.e., PRC2.1 and PRC2.2). 
Chromatin binding and enzyme activity of PRC2 is conferred by the unique roles of its core components. EZH2 contains both a SANT domain, allowing it to bind histones, and a catalytic SET domain, containing its H3K27 methyltransferase activity (Laible et al. 1997). SUZ12 is a zinc finger protein responsible for both DNA and RNA binding, whereas EED performs PRC2's reader function by recognizing methylated H3K27 residues (Schuettengruber et al. 2017). Although EZH2 is PRC2's catalytic subunit, both EED and SUZ12 are important for maintaining PRC2 integrity and enzyme function (Pasini et al. 2004; Montgomery et al. 2007).

Each PRC2 core component is required for mammalian embryogenesis, as global loss of any one of them in mice results in embryonic lethality (Faust et al. 1995; O'Carroll et al. 2001; Pasini et al. 2004). Consistent with impaired cellular proliferation, homozygous-null embryos are smaller in size than wild-type embryos and do not survive past midgestation (Faust et al. 1995; O'Carroll et al. 2001; Cao and Zhang 2004; Pasini et al. 2004). Classically, PcG components were described in Drosophila as suppressors of the homeotic HOX gene cluster, which control body segmentation and morphology during embryogenesis (Lewis 1978; Pirrotta 1998). PRC2 has retained conserved functions across phyla, binding to genes involved in development, morphogenesis, organogenesis, and neurogenesis in both human and murine embryonic stem cells (Boyer et al. 2006; Bracken et al. 2006; Lee et al. 2006). Many of the pathways suppressed by PRC2 are conserved between fruit flies, mice, and humans, including genes important for Wnt, transforming growth factor- $\beta$, fibroblast growth factor, Notch, and Hedgehog signaling (Bracken et al. 2006). Given the number of developmental pathways regulated by PRC2, the mechanisms of dysfunctional embryogenesis in PRC2 mutant models described above are diverse and multifaceted. Although global knockout of core PRC2 components is lethal in mice, global "knockdown" causes a range of phenotypes in humans, as evidenced by the range of severities attributable to partial loss-of-function (LoF) mutations ascertained in human patients.

\section{Disorders of H3K27 Methylation: PRC2-Related Overgrowth Syndromes}

PRC2-related overgrowth syndromes (Table 1) consist of Weaver syndrome (OMIM \#277590), Cohen-Gibson syndrome (OMIM \#617561), and SUZ12-related overgrowth, the latter of which is the least well-characterized of the three. All are autosomal dominant disorders, although most cases are observed sporadically, without prior family history. Weaver

\begin{tabular}{|c|c|c|}
\hline Parameter & PRC2-related overgrowth & Rubinstein-Taybi syndrome \\
\hline Rare disease subtypes (gene) & $\begin{array}{l}\text { Weaver syndrome }(E Z H 2), \text { Cohen-Gibson } \\
\text { syndrome (EED), SUZ12-related } \\
\text { overgrowth (SUZ12) }\end{array}$ & RSTS1 (CREBBP), RSTS2 (EP300) \\
\hline $\begin{array}{l}\text { Canonical histone modification affecting } \\
\text { transcription }\end{array}$ & H3K27me1-3 & H3K27ac \\
\hline Putative mechanism & Partial loss of function & Haploinsufficiency \\
\hline General skeletal phenotype & $\begin{array}{l}\text { Tall stature/macrocephaly, advanced bone } \\
\text { age }\end{array}$ & Short stature, broad thumbs/halluces \\
\hline Intellectual disability & Mild to severe & Mild to severe \\
\hline Cancer predisposition & $\begin{array}{l}\text { Acute myeloid leukemia, acute } \\
\text { lymphoblastic leukemia, neuroblastoma }\end{array}$ & $\begin{array}{l}\text { Diffuse large B-cell lymphoma, } \\
\text { neuroblastoma, rhabdomyosarcoma, } \\
\text { medulloblastoma, meningiomas, } \\
\text { pilomatrixomas }\end{array}$ \\
\hline
\end{tabular}


syndrome is caused by pathogenic variants in EZH2 (Tatton-Brown et al. 2011; Gibson et al. 2012), resulting in partial LoF of PRC2 methyltransferase activity (Cohen et al. 2016; Lui et al. 2018). All EZH2 mutations currently described to cause Weaver syndrome are either missense variants or truncating variants of the last exon (Tatton-Brown et al. 2018). Rare de novo mutations in EED were recently reported to cause Cohen-Gibson syndrome (Cohen et al. 2015; Cohen and Gibson 2016), whereas SUZ12-related overgrowth (also referred to as Weaver-like syndrome) is caused by rare variants in its namesake gene (Imagawa et al. 2017; Imagawa et al. 2018; Cyrus et al. 2019). Similar to Weaver syndrome, reported mutations in EED and SUZ12 impair H3K27me3 formation (Imagawa et al. 2017), in line with the role these core components play in stabilizing PRC2 enzyme function.

PRC2-related overgrowth syndromes present with accelerated pre- and postnatal growth (i.e., tall stature, macrocephaly), advanced bone age, distinctive facial features, and mild-tosevere intellectual disability. Whereas many of these features are common to all three, phenotypic differences do exist between Weaver syndrome, Cohen-Gibson syndrome, and SUZ12-related overgrowth; these differences are succinctly reviewed elsewhere for interested readers (Cyrus et al. 2019). It is challenging to reconcile pathophysiological insight from studies globally knocking out core PRC2 components in mice with their respective human overgrowth syndromes, because PRC2 knockout animals are typically not viable and invariably small, not large. Furthermore, conditional knockout of PRC2 function has brought forth some controversy regarding the cellular mechanism causing overgrowth. For example, loss of either Ezh2 or Eed from murine chondrocytes severely retards skeletal growth by impairing cellular proliferation and hypertrophy (Lui et al. 2016; Mirzamohammadi et al. 2016). Although these studies have led some to suggest Weaver syndrome mutations cause skeletal overgrowth by a gain-of-function mechanism (Lui et al. 2016), this does not appear to be the case, because Weaver mutations display impaired methyltransferase activity in vitro and in vivo (Cohen et al. 2016; Lui et al. 2018).

Recently, Lui et al. (2018) made a Weaver syndrome mouse harboring a patient-derived c.1876G > A (p.V626M) missense mutation. Consistent with other variants, p.V626M was shown to be a partial LoF mutant, with heterozygous and homozygous embryos showing a dose-dependent reduction of H3K27me2-3 (Lui et al. 2018). Although homozygous Weaver syndrome mice were not viable, heterozygous mice survived and were moderately heavier than controls as they aged (Lui et al. 2018). Surprisingly, the overgrowth of the Weaver mice appears to be the result of organomegaly and not the skeletal overgrowth typical of Weaver syndrome patients (Lui et al. 2018). However, organomegaly was not initially reported in their patient, so it is currently unclear why p.V626M results in pathophysiological differences between mice and human. To our knowledge, mice harboring human mutations in Eed and Suz12 have yet to be reported.

So why then does impaired PRC2 function cause a pronounced overgrowth phenotype only in humans? Ultimately, the answer may relate to the degree to which H3K27 methylation is disrupted and to the specific loci missing this histone mark. Mice missing just one copy of core PRC2 components may experience catastrophic growth failure because H3K27 methylation is missing at genes integral for maintaining cell identity, viability, and survival. Alternatively, a variety of genes that promote cellular differentiation may fail to be suppressed in the absence of sufficient H3K27 methylation. These mechanisms may account for the predisposition to hematological malignancies that is observed in Weaver syndrome (Table 1). The extent to which constitutional mutations in EED and SUZ12 might predispose to hematological or other malignancies remains to be clarified.

The degree to which loss of function occurs in vivo for PRC2-related overgrowth syndromes (other than p.V626M) is unclear. Although a 50\% reduction in PRC2 function might be lethal to most mice, partial loss of function from a missense allele might cause a redistribution of PRC2 across the genome, allowing maintenance of cell-specific identity at the 
expense of depressing pathways controlling cell expansion and size. We imagine that complete LoF mutations in human PRC2 components are not compatible with life, because stop-gain mutations near the amino terminus have not been reported to date, although some patients with deletions that include one copy of EZH2 have been reported. Given that there is a reciprocal nature between H3K27 methylation and acetylation (Deevy and Bracken 2019), future studies modeling PRC2 variants should consider which genes missing $\mathrm{H} 3 \mathrm{~K} 27 \mathrm{me} 3$ at their promoters subsequently acquire the acetylation mark.

\section{p300 and CBP Are H3K27 Acetyltransferases}

Acetylation of H3K27 is associated with transcriptional activation because it loosens DNA contacts from core histones, thereby enabling basal transcriptional machinery to interact with gene promoters. Although a number of histone acetyltransferases (HATs) exist with differing histone and protein substrate specificities, the ubiquitously expressed transcriptional coactivators CREB-binding protein (CBP) and p300 are responsible for writing H3K27ac (Jin et al. 2011; Lasko et al. 2017). CBP and p300 belong to the KAT3 family of HATs and are believed to be functionally homologous because they share $~ 57 \%$ structural similarity at the protein level, with $88 \%$ sequence homology between their HAT domains (Bedford et al. 2010; Lipinski et al. 2019).

CBP and p300 integrate signals from numerous biological pathways. They can physically interact with more than 400 different proteins, many of which are transcription factors (Bedford et al. 2010). Although CBP and p300 play a major role in chromatin remodeling by writing H3K27ac, recently H2B has also been shown to be a major target of their HAT activity, as have thousands of different sites on nonhistone proteins (Weinert et al. 2018), suggesting they are a control node for enzymes and transcription factors. Thus, CBP and p300 protein scaffolding and acetyltransferase functions coordinate biological programs with a stunning level of complexity, operating within a diversity of cell types (Bedford et al. 2010; Dyson and Wright 2016).

\section{Mutations in EP300 and CREBBP Cause Rubinstein-Taybi Syndrome}

Both p300 and CBP are integral for proper growth and development, as evident by the rare autosomal dominant disorder Rubinstein-Taybi syndrome (RSTS) (Table 1). RSTS affects $1: 100,000$ to $1: 125,000$ live births (Stevens 1993) and is classified as either RSTS1 (OMIM \#180849) or RSTS2 (OMIM \#613684) resulting from heterozygous pathogenic variants in either the CREBBP or EP300 genes, respectively. RSTS is characterized by distinctive facial features, broad thumbs and halluces, and mild-to-severe intellectual disability, but unlike PRC2-related overgrowth syndromes, RSTS patients are typically short in stature (Stevens 1993). At some level, p300/CBP can be considered to act as tumor suppressors, because instances of both benign and malignant tumors have been reported in RSTS patients (Boot et al. 2018). Based on the increased incidence of tumors in RSTS patients, we can infer that not only are sufficient quantities of acetyl marks on H3K27, H2B, and other nonhistone proteins required during fetal development, but maintenance of these PTMs is required throughout postnatal life for cells to retain a fully differentiated and functional adult state.

As was found with deletion of PRC2 members, global deletion of p300 or CBP individually in mice causes lethality midgestation (Yao et al. 1998; Tanaka et al. 2000). These embryos are severely growth-retarded and show signs of defective neural tube closure, exencephaly, cardiac anomalies, and brain hemorrhaging. Importantly, these findings indicate that p300 and CBP function are not completely redundant, and that each HAT governs distinctive pathways critical for embryogenesis. One reason for this is that p300 and CBP have overlapping but distinct expression profiles throughout stages of mouse embryogenesis (Yao et al. 1998; 
Bhattacherjee et al. 2009). Thus, CBP and p300 control a unique set of genes and nonhistone PTMs that are both spatially and temporally restricted. Furthermore, mice heterozygous for both Crebbp and Ep300 display a similar embryologic phenotype to global single knockout embryos (Yao et al. 1998), suggesting that a full genomic complement of these HATs are essential for normal development.

Despite the early lethality caused by p300 or CBP deletion in mice, haploinsufficient mouse models are viable; however, they do have marked growth and morphological phenotypes (Tanaka et al. 1997, 2000; Oike et al. 1999). Initially, mice with a single copy of Crebbp were reported as smaller and recapitulated several features reported in patients with RSTS (albeit with variable penetrance), including enlarged anterior fontanels and abnormal skeletal patterning, but without hallmark RSTS features like broad first phalanges (Tanaka et al. 1997). Similarly, mice carrying one copy of a truncated form of CBP showed pre- and postnatal growth retardation, distinctive facial features (e.g., broad nasal bridge, short nose), and frequent cardiac anomalies (Oike et al. 1999).

To our knowledge, targeted deletion studies of p300 or CBP from mouse chondrocytes or osteoblasts in vivo (similar to those described above for PRC2 core members) have not been done. However, a number of in vitro and cell-based studies have shown p300/CBP are important for enhancing the transcriptional activity and/or gene expression of regulators of chondrocyte and osteoblast differentiation, such as Sox9 (Tsuda et al. 2003; Furumatsu et al. 2005; Imamura et al. 2005), mammalian Runt domain protein 2/core binding factor a1 (Sierra et al. 2003), and cartilage homeoprotein-1 (lioka et al. 2003).

Determining the unique p300 and CBP-dependent genes and nonhistone PTMs responsible for hallmark features of RSTS will prove to be difficult. In addition to being associated with active gene promoters, $\mathrm{H} 3 \mathrm{~K} 27 \mathrm{ac}$ in particular is a feature of active enhancers, enabling the occupancy of transcription factors at unique noncoding regions to control target genes via long-range chromatin interactions. Using p300 chromatin immunoprecipitation followed by sequencing (ChIP-seq) to predict tissue-specific enhancers, thousands of p300-binding sites have been identified in murine limb buds and neural tissues at midgestation alone (Visel et al. 2009). Determining the functional relevance of these regions in vivo with respect to normal growth and development will require targeted deletion followed by deep phenotyping. Although two enhancers (i.e., M280 and M1442) previously identified by Visel et al. (2009) were predicted to affect limb development, neither of them were obligatory for proper limb formation and morphology, although loss of M280 resulted in smaller mice (Nolte et al. 2014); this finding is in line with the generalized growth retardation of RSTS. It remains to be seen which genes M280 regulates, which tissues it is important for forming/maintaining, and whether this enhancer is truly dependent on P300's HAT function. Thus, although $\mathrm{CBP}$ and $\mathrm{p} 300 \mathrm{ChIP}$-seq will yield valuable information regarding the unique subsets of gene promoters that depend on their HAT function, we must also consider the role of CBP and p300 in forming active enhancers. Furthermore, future studies examining RSTS pathophysiology should also consider the role of $\mathrm{H} 2 \mathrm{~B}$ hypoacetylation and $\mathrm{p} 300 / \mathrm{CBP}^{\prime} \mathrm{s}$ various other nonhistone substrates.

Although the function of $\mathrm{p} 300 / \mathrm{CBP}$ as coactivators of numerous signaling proteins makes it difficult to deconvolute the various role of H3K27ac in the molecular etiology of RSTS, some studies have attempted to overcome this by developing mice carrying site-specific mutations, such as those removing CBP HAT function while preserving its protein-binding domains (Korzus et al. 2004). Selective loss of HAT activity from forebrain neurons impairs the ability of these mice to form long-term memory (Korzus et al. 2004), a finding consistent with studies of both haploinsufficient RSTS mouse models (Oike et al. 1999; Alarcon et al. 2004) and total loss of CBP coactivator function from forebrain principal neurons (Valor et al. 2011). Together, these studies may directly implicate impaired chromatin remodeling in causing aspects of intellectual disability seen in RSTS. 


\section{Epigenetic Therapies Affecting H3K27 Modifications}

Knowledge of the molecular mechanisms behind rare human genetic disorders is often presented as a necessary step toward targeted therapies to improve outcomes. However, the geographic dispersal of the patients makes case accrual and standardized medical assessment difficult. Similarly, the length of time required to observe a measurable difference in growth velocity and/or neurodevelopment makes proper placebo-controlled trials (even crossover trials) challenging, to say the least. It is likely, then, that the first personalized therapies for PRC2-related overgrowth and Rubinstein-Taybi syndrome will appear in the context of personalized oncogenomics. Such a scenario is likely to arise when treating physicians wish to make use of the prior knowledge of the underlying syndrome (e.g., Weaver syndrome or RSTS) to make educated additions to standardized treatment regimens for whatever neoplasms might arise in these patients.

Although EZH2 inhibitors are in development for a variety of indications, it seems unlikely that these drugs would confer obvious benefit to a patient with Weaver syndrome, because the preexisting partial loss of H3K27 methyltransferase activity would be exacerbated by an EZH2 inhibitor, rather than mitigated by it.

With respect to tumors or leukemias arising in RSTS patients, some clinical traction may be gained in considering the use of histone deacetylase (HDAC) inhibitors such as valproic acid (Phiel et al. 2001). The rationale for this indirect approach would involve the inhibition of histone deacetylases, in an attempt to preserve H3K27ac marks (and acetylation of other histone/nonhistone residues) that were already diminished by the preexisting reduction in HAT activity. Although speculative, the reciprocal nature of H3K27 methyl and acetyl marks may warrant consideration of HAT inhibition for Weaver syndrome in an attempt to dampen genes derepressed by impaired methyltransferase activity. Conversely, PRC2 inhibition may "lift the break" on loci indirectly suppressed in the absence of sufficient p300/CBP activity. Recently, the compound A-485 has been described as a highly selective p300/CBP HAT inhibitor capable of impairing H3K27/18ac formation along with proliferation of various solid state and hematological cancer-cell lines (Lasko et al. 2017; Michaelides et al. 2018). Whereas A-485 may hold therapeutic relevance in treating some malignancies, it will likely also prove useful in cell-based assays aimed at defining the specific genes regulated by p300/CBP HAT function that are causative of RSTS phenotypes. It may also be valuable for proof-of-concept studies designed to prevent excessive H3K27ac in the context of PRC2 LoF. Given that preclinical mouse models are expensive to generate, patient-derived induced pluripotent stem cells (iPSCs) will serve as an important model system to assess mutation-specific changes in cellular function and also as a test of the mechanisms that might be engaged by HDAC therapies. To date, only a few studies have generated iPCS-derived neurons from RSTS1 and RSTS2 patients (Alari et al. 2018a,b), so this represents a fruitful area to study the pathophysiology of aberrant H3K27ac deposition.

\section{CONCLUSION}

Proper embryogenesis and postnatal growth is dependent on reciprocal modifications to H3K27, which are catalyzed by PRC2 and p300/CBP. The importance of H3K27 as a molecular switch is evidenced by PRC2-related overgrowth disorders and Rubinstein-Taybi syndrome. These rare diseases have opposing skeletal growth phenotypes, which may be associated with impairments in their underlying epigenetic writers to properly silence or activate gene transcription, respectively. Although mouse knockout studies have revealed the requirement of PRC2 core components and p300/CBP for development, few have managed to accurately model their respective human syndromes. Although species-specific differences in PRC2 or HAT requirements may explain this, it is likely that even a 50\% reduction in 
Competing Interest Statement

The authors have declared no competing interest. their enzyme function is catastrophic for cellular viability in mice, preventing detailed studies throughout their lifespan. Instead, partial LoF variants may allow a redistribution of these epigenetic writers across the genome and proteome to maintain control of pathways governing cell survival at the expense of those regulating proliferation and size. Given their well-established role in gene expression, it will be of interest going forward to determine which gene sets depleted of $\mathrm{H} 3 \mathrm{~K} 27 \mathrm{ac}$ or $\mathrm{H} 3 \mathrm{~K} 27$ me1-3 become reciprocally repressed or activated in order to determine the direct and indirect effects PRC2 or p300/CBP mutations.

\section{ADDITIONAL INFORMATION}

\section{Author Contributions}

Both D.G. and W.T.G. conceived and wrote the manuscript.

\section{Funding}

D.G. is supported by a Michael Smith Foundation for Health Research (MSFHR) postdoctoral fellowship, and W.T.G. holds intramural salary support from the BC Children's Hospital Research Institute. W.T.G. also holds Canadian Institutes of Health Research (CIHR) project grant funds (MOP-119595 and PJT-148695).

\section{REFERENCES}

Alarcon JM, Malleret G, Touzani K, Vronskaya S, Ishii S, Kandel ER, Barco A. 2004. Chromatin acetylation, memory, and LTP are impaired in $\mathrm{CBP}^{+/-}$mice: a model for the cognitive deficit in Rubinstein-Taybi syndrome and its amelioration. Neuron 42: 947-959. doi:10.1016/j.neuron.2004.05.021

Alari V, Russo S, Rovina D, Gowran A, Garzo M, Crippa M, Mazzanti L, Scalera C, Prosperi E, Giardino D, et al. 2018a. Generation of the Rubinstein-Taybi syndrome type 2 patient-derived induced pluripotent stem cell line (IAli001-A) carrying the EP300 exon 23 stop mutation c.3829A>T, p.(Lys1277*). Stem Cell Res 30: 175179. doi:10.1016/j.scr.2018.06.009

Alari V, Russo S, Terragni B, Ajmone PF, Sironi A, Catusi I, Calzari L, Concolino D, Marotta R, Milani D, et al. 2018b. iPSC-derived neurons of CREBBP- and EP300-mutated Rubinstein-Taybi syndrome patients show morphological alterations and hypoexcitability. Stem Cell Res 30: 130-140. doi:10.1016/j.scr.2018 .05 .019

Bedford DC, Kasper LH, Fukuyama T, Brindle PK. 2010. Target gene context influences the transcriptional requirement for the KAT3 family of CBP and p300 histone acetyltransferases. Epigenetics 5: 9-15. doi:10 .4161/epi.5.1.10449

Bhattacherjee V, Horn KH, Singh S, Webb CL, Pisano MM, Greene RM. 2009. CBP/p300 and associated transcriptional co-activators exhibit distinct expression patterns during murine craniofacial and neural tube development. Int J Dev Biol 53: 1097-1104. doi:10.1387/ijdb.072489vb

Boot MV, van Belzen MJ, Overbeek LI, Hijmering N, Mendeville M, Waisfisz Q, Wesseling P, Hennekam RC, de Jong D. 2018. Benign and malignant tumors in Rubinstein-Taybi syndrome. Am J Med Genet A 176: $597-$ 608. doi:10.1002/ajmg.a.38603

Boyer LA, Plath K, Zeitlinger J, Brambrink T, Medeiros LA, Lee TI, Levine SS, Wernig M, Tajonar A, Ray MK, et al. 2006. Polycomb complexes repress developmental regulators in murine embryonic stem cells. Nature 441: 349-353. doi:10.1038/nature04733

Bracken AP, Dietrich N, Pasini D, Hansen KH, Helin K. 2006. Genome-wide mapping of Polycomb target genes unravels their roles in cell fate transitions. Genes Dev 20: 1123-1136. doi:10.1101/gad.381706

Cao R, Zhang Y. 2004. SUZ12 is required for both the histone methyltransferase activity and the silencing function of the EED-EZH2 complex. Mol Cell 15: 57-67. doi:10.1016/j.molcel.2004.06.020

Cao R, Wang L, Wang H, Xia L, Erdjument-Bromage H, Tempst P, Jones RS, Zhang Y. 2002. Role of histone H3 lysine 27 methylation in Polycomb-group silencing. Science 298: 1039-1043. doi:10.1126/science .1076997

Cohen AS, Gibson WT. 2016. EED-associated overgrowth in a second male patient. J Hum Genet 61: 831834. doi:10.1038/jhg.2016.51 
Cohen AS, Tuysuz B, Shen Y, Bhalla SK, Jones SJ, Gibson WT. 2015. A novel mutation in EED associated with overgrowth. J Hum Genet 60: 339-342. doi:10.1038/jhg.2015.26

Cohen AS, Yap DB, Lewis ME, Chijiwa C, Ramos-Arroyo MA, Tkachenko N, Milano V, Fradin M, McKinnon ML, Townsend KN, et al. 2016. Weaver syndrome-associated EZH2 protein variants show impaired histone methyltransferase function in vitro. Hum Mutat 37: 301-307. doi:10.1002/humu.22946

Cyrus SS, Cohen ASA, Agbahovbe R, Avela K, Yeung KS, Chung BHY, Luk HM, Tkachenko N, Choufani S, Weksberg R, et al. 2019. Rare SUZ12 variants commonly cause an overgrowth phenotype. Am J Med Genet C Semin Med Genet 181: 532-547. doi:10.1002/ajmg.c.31748

Deevy O, Bracken AP. 2019. PRC2 functions in development and congenital disorders. Development 146: dev181354. doi:10.1242/dev.181354

Dyson HJ, Wright PE. 2016. Role of intrinsic protein disorder in the function and interactions of the transcriptional coactivators CREB-binding protein (CBP) and p300. J Biol Chem 291: 6714-6722. doi:10.1074/jbc .R115.692020

Faust C, Schumacher A, Holdener B, Magnuson T. 1995. The EED mutation disrupts anterior mesoderm production in mice. Development 121: 273-285.

Furumatsu T, Tsuda M, Taniguchi N, Tajima Y, Asahara H. 2005. Smad3 induces chondrogenesis through the activation of SOX9 via CREB-binding protein/p300 recruitment. J Biol Chem 280: 8343-8350. doi:10 1074/jbc.M413913200

Gibson WT, Hood RL, Zhan SH, Bulman DE, Fejes AP, Moore R, Mungall AJ, Eydoux P, Babul-Hirji R, An J, et al. 2012. Mutations in EZH2 cause Weaver syndrome. Am J Hum Genet 90: 110-118. doi:10.1016/j .ajhg.2011.11.018

Goyal D, Limesand SW, Goyal R. 2019. Epigenetic responses and the developmental origins of health and disease. J Endocrinol 242: T105-T119. doi:10.1530/JOE-19-0009

lioka T, Furukawa K, Yamaguchi A, Shindo H, Yamashita S, Tsukazaki T. 2003. P300/CBP acts as a coactivator to cartilage homeoprotein-1 (Cart1), paired-like homeoprotein, through acetylation of the conserved lysine residue adjacent to the homeodomain. J Bone Miner Res 18: 1419-1429. doi:10.1359/jbmr.2003.18.8 .1419

Imagawa E, Higashimoto K, Sakai Y, Numakura C, Okamoto N, Matsunaga S, Ryo A, Sato Y, Sanefuji M, Ihara K, et al. 2017. Mutations in genes encoding Polycomb repressive complex 2 subunits cause Weaver syndrome. Hum Mutat 38: 637-648. doi:10.1002/humu.23200

Imagawa E, Albuquerque EVA, Isidor B, Mitsuhashi S, Mizuguchi T, Miyatake S, Takata A, Miyake N, Boguszewski MCS, Boguszewski CL, et al. 2018. Novel SUZ12 mutations in Weaver-like syndrome. Clin Genet 94: 461-466. doi:10.1111/cge.13415

Imamura T, Imamura C, Iwamoto Y, Sandell LJ. 2005. Transcriptional co-activators CREB-binding protein/ p300 increase chondrocyte $\mathrm{Cd}$-rap gene expression by multiple mechanisms including sequestration of the repressor CCAAT/enhancer-binding protein. J Biol Chem 280: 16625-16634. doi:10.1074/jbc M411469200

Jin Q, Yu LR, Wang L, Zhang Z, Kasper LH, Lee JE, Wang C, Brindle PK, Dent SY, Ge K. 2011. Distinct roles of GCN5/PCAF-mediated H3K9ac and CBP/p300-mediated H3K18/27ac in nuclear receptor transactivation. EMBO J 30: 249-262. doi:10.1038/emboj.2010.318

Kalkhoven E. 2004. CBP and p300: HATs for different occasions. Biochem Pharmacol 68: 1145-1155. doi:10 .1016/j.bcp.2004.03.045

Korzus E, Rosenfeld MG, Mayford M. 2004. CBP histone acetyltransferase activity is a critical component of memory consolidation. Neuron 42: 961-972. doi:10.1016/j.neuron.2004.06.002

Laible G, Wolf A, Dorn R, Reuter G, Nislow C, Lebersorger A, Popkin D, Pillus L, Jenuwein T. 1997. Mammalian homologues of the Polycomb-group gene Enhancer of zeste mediate gene silencing in Drosophila heterochromatin and at S. cerevisiae telomeres. EMBO J 16: 3219-3232. doi:10.1093/ emboj/16.11.3219

Lasko LM, Jakob CG, Edalji RP, Qiu W, Montgomery D, Digiammarino EL, Hansen TM, Risi RM, Frey R, Manaves V, et al. 2017. Discovery of a selective catalytic p300/CBP inhibitor that targets lineage-specific tumours. Nature 550: 128-132. doi:10.1038/nature24028

Lee TI, Jenner RG, Boyer LA, Guenther MG, Levine SS, Kumar RM, Chevalier B, Johnstone SE, Cole MF, Isono $\mathrm{K}$, et al. 2006. Control of developmental regulators by Polycomb in human embryonic stem cells. Cell 125: 301-313. doi:10.1016/j.cell.2006.02.043

Lewis EB. 1978. A gene complex controlling segmentation in Drosophila. Nature 276: 565-570. doi:10.1038/ $276565 \mathrm{a} 0$

Lewis A, Mitsuya K, Umlauf D, Smith P, Dean W, Walter J, Higgins M, Feil R, Reik W. 2004. Imprinting on distal chromosome 7 in the placenta involves repressive histone methylation independent of DNA methylation. Nat Genet 36: 1291-1295. doi:10.1038/ng1468

Lipinski M, Del Blanco B, Barco A. 2019. CBP/p300 in brain development and plasticity: disentangling the KAT's cradle. Curr Opin Neurobiol 59: 1-8. doi:10.1016/j.conb.2019.01.023 
Lui JC, Garrison P, Nguyen Q, Ad M, Keembiyehetty C, Chen W, Jee YH, Landman E, Nilsson O, Barnes KM, et al. 2016. EZH1 and EZH2 promote skeletal growth by repressing inhibitors of chondrocyte proliferation and hypertrophy. Nat Commun 7: 13685. doi:10.1038/ncomms13685

Lui JC, Barnes KM, Dong L, Yue S, Graber E, Rapaport R, Dauber A, Nilsson O, Baron J. 2018. Ezh2 mutations found in the Weaver overgrowth syndrome cause a partial loss of H3K27 histone methyltransferase activity. J Clin Endocrinol Metab 103: 1470-1478. doi:10.1210/jc.2017-01948

Michaelides MR, Kluge A, Patane M, Van Drie JH, Wang C, Hansen TM, Risi RM, Mantei R, Hertel C, Karukurichi $\mathrm{K}$, et al. 2018. Discovery of spiro oxazolidinediones as selective, orally bioavailable inhibitors of p300/CBP histone acetyltransferases. ACS Med Chem Lett 9: 28-33. doi:10.1021/acsmedchemlett.7b00395

Mirzamohammadi F, Papaioannou G, Inloes JB, Rankin EB, Xie H, Schipani E, Orkin SH, Kobayashi T. 2016. Polycomb repressive complex 2 regulates skeletal growth by suppressing Wnt and TGF- $\beta$ signalling. Nat Commun 7: 12047. doi:10.1038/ncomms12047

Montgomery ND, Yee D, Montgomery SA, Magnuson T. 2007. Molecular and functional mapping of EED motifs required for PRC2-dependent histone methylation. J Mol Biol 374: 1145-1157. doi:10.1016/j.jmb 2007.10.040

Munshi A, Shafi G, Aliya N, Jyothy A. 2009. Histone modifications dictate specific biological readouts. J Genet Genomics 36: 75-88. doi:10.1016/S1673-8527(08)60094-6

Nolte MJ, Wang Y, Deng JM, Swinton PG, Wei C, Guindani M, Schwartz RJ, Behringer RR. 2014. Functiona analysis of limb transcriptional enhancers in the mouse. Evol Dev 16: 207-223. doi:10.1111/ede.12084

O'Carroll D, Erhardt S, Pagani M, Barton SC, Surani MA, Jenuwein T. 2001. The Polycomb-group gene Ezh2 is required for early mouse development. Mol Cell Biol 21: 4330-4336. doi:10.1128/MCB.21.13.4330-4336 .2001

Oike Y, Hata A, Mamiya T, Kaname T, Noda Y, Suzuki M, Yasue H, Nabeshima T, Araki K, Yamamura K. 1999. Truncated CBP protein leads to classical Rubinstein-Taybi syndrome phenotypes in mice: implications for a dominant-negative mechanism. Hum Mol Genet 8: 387-396. doi:10.1093/hmg/8.3.387

Pasini D, Bracken AP, Jensen MR, Lazzerini Denchi E, Helin K. 2004. Suz12 is essential for mouse development and for EZH2 histone methyltransferase activity. EMBO J 23: 4061-4071. doi:10.1038/sj.emboj .7600402

Phiel CJ, Zhang F, Huang EY, Guenther MG, Lazar MA, Klein PS. 2001. Histone deacetylase is a direct target of valproic acid, a potent anticonvulsant, mood stabilizer, and teratogen. J Biol Chem 276: 36734-36741. doi:10.1074/jbc.M101287200

Pirrotta V. 1998. Polycombing the genome: PcG, trxG, and chromatin silencing. Cell 93: 333-336. doi:10 .1016/S0092-8674(00)81162-9

Plath K, Fang J, Mlynarczyk-Evans SK, Cao R, Worringer KA, Wang H, de la Cruz CC, Otte AP, Panning B, Zhang Y. 2003. Role of histone H3 lysine 27 methylation in X inactivation. Science 300: 131-135. doi:10.1126/sci ence.1084274

Ringrose L, Paro R. 2004. Epigenetic regulation of cellular memory by the Polycomb and Trithorax group proteins. Annu Rev Genet 38: 413-443. doi:10.1146/annurev.genet.38.072902.091907

Roth SY, Denu JM, Allis CD. 2001. Histone acetyltransferases. Annu Rev Biochem 70: 81-120. doi:10.1146/ annurev.biochem.70.1.81

Schuettengruber B, Bourbon HM, Di Croce L, Cavalli G. 2017. Genome regulation by Polycomb and Trithorax: 70 years and counting. Cell 171: 34-57. doi:10.1016/j.cell.2017.08.002

Sierra J, Villagra A, Paredes R, Cruzat F, Gutierrez S, Javed A, Arriagada G, Olate J, Imschenetzky M, Van Wijnen AJ, et al. 2003. Regulation of the bone-specific osteocalcin gene by $\mathrm{p} 300$ requires Runx2/Cbfa1 and the vitamin D3 receptor but not p300 intrinsic histone acetyltransferase activity. Mol Cell Biol 23: 3339-3351. doi:10.1128/MCB.23.9.3339-3351.2003

Silva J, Mak W, Zvetkova I, Appanah R, Nesterova TB, Webster Z, Peters AH, Jenuwein T, Otte AP, Brockdorff N. 2003. Establishment of histone $h 3$ methylation on the inactive $X$ chromosome requires transient recruitment of Eed-Enx1 Polycomb group complexes. Dev Cell 4: 481-495. doi:10.1016/S1534-5807(03)00068-6

Sneppen K, Ringrose L. 2019. Theoretical analysis of Polycomb-Trithorax systems predicts that poised chromatin is bistable and not bivalent. Nat Commun 10: 2133. doi:10.1038/s41467-019-10130-2

Stevens CA. 1993. Rubinstein-Taybi syndrome. In GeneReviews ${ }^{\circledR}$ (ed. Adam MP, Ardinger HH, Pagon RA, et al.), pp. 1-17. University of Washington, Seattle, WA.

Strahl BD, Allis CD. 2000. The language of covalent histone modifications. Nature 403: 41-45. doi:10.1038/ 47412

Tanaka Y, Naruse I, Maekawa T, Masuya H, Shiroishi T, Ishii S. 1997. Abnormal skeletal patterning in embryos lacking a single Cbp allele: a partial similarity with Rubinstein-Taybi syndrome. Proc Natl Acad Sci 94: 10215-10220. doi:10.1073/pnas.94.19.10215

Tanaka Y, Naruse I, Hongo T, Xu M, Nakahata T, Maekawa T, Ishii S. 2000. Extensive brain hemorrhage and embryonic lethality in a mouse null mutant of CREB-binding protein. Mech Dev 95: 133-145. doi:10 1016/S0925-4773(00)00360-9 
Tatton-Brown K, Hanks S, Ruark E, Zachariou A, Duarte Sdel V, Ramsay E, Snape K, Murray A, Perdeaux ER, Seal $\mathrm{S}$, et al. 2011. Germline mutations in the oncogene EZH2 cause Weaver syndrome and increased human height. Oncotarget 2: 1127-1133. doi:10.18632/oncotarget.385

Tatton-Brown K, Hanks S, Ruark E, Zachariou A, Del Vecchio Duarte S, Ramsay E, Snape K, Murray A, Perdeaux ER, Seal S, et al. 2018. Correction: germline mutations in the oncogene EZH2 cause Weaver syndrome and increased human height. Oncotarget 9: 36719. doi:10.18632/oncotarget.26429

Tsuda M, Takahashi S, Takahashi Y, Asahara H. 2003. Transcriptional co-activators CREB-binding protein and p300 regulate chondrocyte-specific gene expression via association with Sox9. J Biol Chem 278: 2722427229. doi:10.1074/jbc.M303471200

Valor LM, Pulopulos MM, Jimenez-Minchan M, Olivares R, Lutz B, Barco A. 2011. Ablation of CBP in forebrain principal neurons causes modest memory and transcriptional defects and a dramatic reduction of histone acetylation but does not affect cell viability. J Neurosci 31: 1652-1663. doi:10.1523/JNEUROSCI.4737-10 .2011

Visel A, Blow MJ, Li Z, Zhang T, Akiyama JA, Holt A, Plajzer-Frick I, Shoukry M, Wright C, Chen F, et al. 2009. ChIP-seq accurately predicts tissue-specific activity of enhancers. Nature 457: 854-858. doi:10.1038/ nature07730

Wang J, Mager J, Chen Y, Schneider E, Cross JC, Nagy A, Magnuson T. 2001. Imprinted X inactivation maintained by a mouse Polycomb group gene. Nat Genet 28: 371-375. doi:10.1038/ng574

Weinert BT, Narita T, Satpathy S, Srinivasan B, Hansen BK, Scholz C, Hamilton WB, Zucconi BE, Wang WW, Liu WR, et al. 2018. Time-resolved analysis reveals rapid dynamics and broad scope of the CBP/p300 acetylome. Cell 174: 231-244 e212. doi:10.1016/j.cell.2018.04.033

Yao TP, Oh SP, Fuchs M, Zhou ND, Ch'ng LE, Newsome D, Bronson RT, Li E, Livingston DM, Eckner R. 1998. Gene dosage-dependent embryonic development and proliferation defects in mice lacking the transcriptional integrator p300. Cell 93: 361-372. doi:10.1016/S0092-8674(00)81165-4

Yu JR, Lee CH, Oksuz O, Stafford JM, Reinberg D. 2019. PRC2 is high maintenance. Genes Dev 33: 903-935. doi:10.1101/gad.325050.119 


\title{
COLD SPRING HARBOR Molecular Case Studies
}

\section{Reciprocal skeletal phenotypes of PRC2-related overgrowth and Rubinstein-Taybi syndromes: potential role of H3K27 modifications}

\author{
Daniel Gamu and William T. Gibson
}

Cold Spring Harb Mol Case Stud 2020, 6: a005058

Access the most recent version at doi: $10.1101 / \mathrm{mcs} . a 005058$

References This article cites 64 articles, 18 of which can be accessed free at: http://molecularcasestudies.cshlp.org/content/6/4/a005058.full.html\#ref-list-1

License This article is distributed under the terms of the Creative Commons Attribution-NonCommercial License, which permits reuse and redistribution, except for commercial purposes, provided that the original author and source are credited.

Email Alerting Receive free email alerts when new articles cite this article - sign up in the box at the Service top right corner of the article or click here. 